\title{
3D fiber deposited polymeric scaffolds for external auditory canal wall
}

Citation for published version (APA):

Mota, C., Milazzo, M., Panetta, D., Trombi, L., Gramigna, V., Salvadori, P. A., Giannotti, S., Bruschini, L., Stefanini, C., Moroni, L., Berrettini, S., \& Danti, S. (2018). 3D fiber deposited polymeric scaffolds for external auditory canal wall. Journal of Materials Science-Materials in Medicine, 29(5), [63]. https://doi.org/10.1007/s10856-018-6071-3

Document status and date:

Published: 01/05/2018

DOI:

10.1007/s10856-018-6071-3

Document Version:

Publisher's PDF, also known as Version of record

Document license:

Taverne

Please check the document version of this publication:

- A submitted manuscript is the version of the article upon submission and before peer-review. There can be important differences between the submitted version and the official published version of record.

People interested in the research are advised to contact the author for the final version of the publication, or visit the DOI to the publisher's website.

- The final author version and the galley proof are versions of the publication after peer review.

- The final published version features the final layout of the paper including the volume, issue and page numbers.

Link to publication

\footnotetext{
General rights rights.

- You may freely distribute the URL identifying the publication in the public portal. please follow below link for the End User Agreement:

www.umlib.nl/taverne-license

Take down policy

If you believe that this document breaches copyright please contact us at:

repository@maastrichtuniversity.nl

providing details and we will investigate your claim.
}

Copyright and moral rights for the publications made accessible in the public portal are retained by the authors and/or other copyright owners and it is a condition of accessing publications that users recognise and abide by the legal requirements associated with these

- Users may download and print one copy of any publication from the public portal for the purpose of private study or research.

- You may not further distribute the material or use it for any profit-making activity or commercial gain

If the publication is distributed under the terms of Article $25 \mathrm{fa}$ of the Dutch Copyright Act, indicated by the "Taverne" license above, 


\title{
Original Research
}

\section{D fiber deposited polymeric scaffolds for external auditory canal wall}

\author{
Carlos Mota ${ }^{1}$ Mario Milazzo ${ }^{2} \cdot$ Daniele Panetta $^{3} \cdot$ Luisa Trombi $^{4} \cdot$ Vera Gramigna $^{5} \cdot$ Piero A. Salvadori $^{3}$. \\ Stefano Giannotti ${ }^{6} \cdot$ Luca Bruschini $^{7} \cdot$ Cesare Stefanini ${ }^{2} \cdot$ Lorenzo Moroni $^{1} \cdot$ Stefano Berrettini ${ }^{7} \cdot$ Serena Danti $\mathbb{C}^{2,8}$
}

Received: 26 November 2017 / Accepted: 21 April 2018 / Published online: 7 May 2018

(c) Springer Science+Business Media, LLC, part of Springer Nature 2018

\begin{abstract}
The external auditory canal (EAC) is an osseocartilaginous structure extending from the auricle to the eardrum, which can be affected by congenital, inflammatory, and neoplastic diseases, thus reconstructive materials are needed. Current biomaterialbased approaches for the surgical reconstruction of EAC posterior wall still suffer from resorption (biological) and extrusion (synthetic). In this study, 3D fiber deposited scaffolds based on poly(ethylene oxide terephthalate)/poly(butylene terephthalate) were designed and fabricated to replace the EAC wall. Fiber diameter and scaffold porosity were optimized, leading to $200 \pm 33 \mu \mathrm{m}$ and $55 \% \pm 5 \%$, respectively. The mechanical properties were evaluated, resulting in a Young's modulus of $25.1 \pm 7.0 \mathrm{MPa}$. Finally, the EAC scaffolds were tested in vitro with osteo-differentiated human mesenchymal stromal cells (hMSCs) with different seeding methods to produce homogeneously colonized replacements of interest for otologic surgery. This study demonstrated the fabrication feasibility of EAC wall scaffolds aimed to match several important requirements for biomaterial application to the ear under the Tissue Engineering paradigm, including shape, porosity, surface area, mechanical properties and favorable in vitro interaction with osteoinduced hMSCs.
\end{abstract}

\section{Graphical Abstract}

This study demonstrated the fabrication feasibility of outer ear canal wall scaffolds via additive manufacturing. Aimed to match several important requirements for biomaterial application to ear replacements under the Tissue Engineering paradigm, including shape, porosity and pore size, surface area, mechanical properties and favorable in vitro interaction with osteo-differentiated mesenchymal stromal cells.

Electronic supplementary material The online version of this article (https://doi.org/10.1007/s10856-018-6071-3) contains supplementary material, which is available to authorized users.

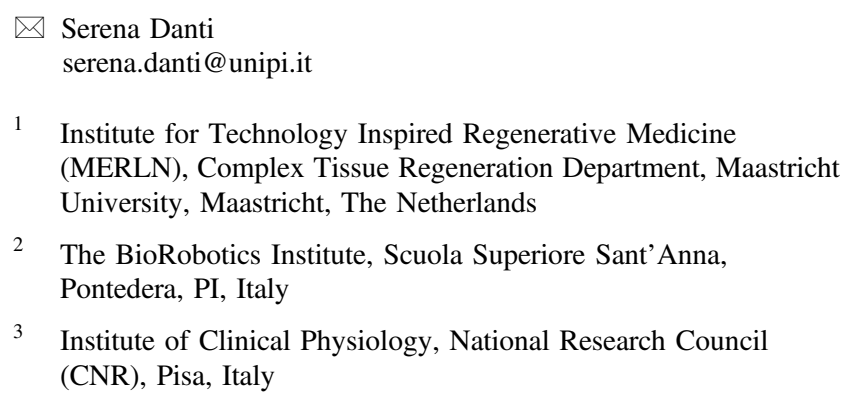

1 Institute for Technology Inspired Regenerative Medicine (MERLN), Complex Tissue Regeneration Department, Maastricht University, Maastricht, The Netherlands

2 The BioRobotics Institute, Scuola Superiore Sant'Anna, Pontedera, PI, Italy

3 Institute of Clinical Physiology, National Research Council (CNR), Pisa, Italy

4 Department of Clinical and Experimental Medicine, University of Pisa, Pisa, Italy

5 Institute of Bioimaging and Molecular Physiology, National Research Council (CNR), Germaneto, CZ, Italy

6 Department of Medical and Surgical Sciences and Neurosciences, University of Siena, Siena, Italy

7 Department of Surgical, Medical, Molecular Pathology and Emergency Medicine, University of Pisa, Pisa, Italy

8 Dept. of Civil and Industrial Engineering, University of Pisa, Largo L. Lazzarino 2, Pisa, Italy 


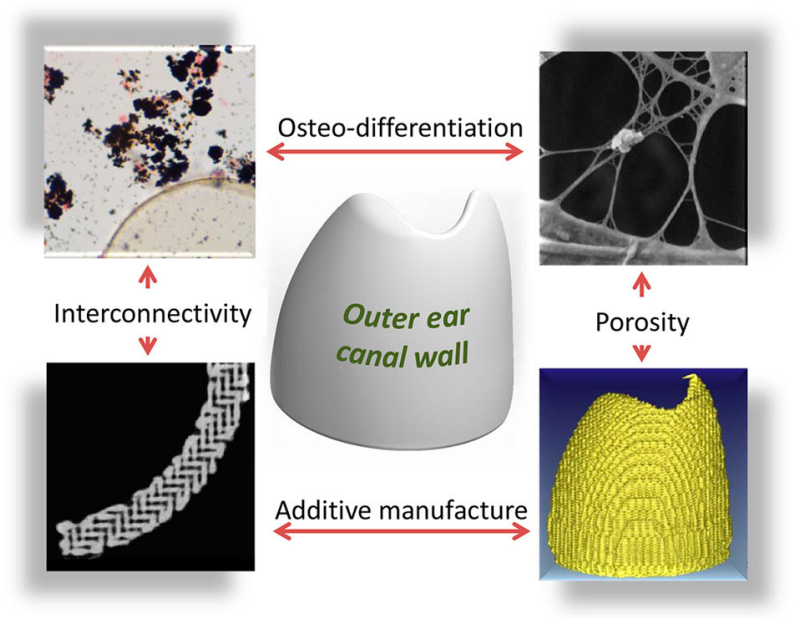

\section{Introduction}

The external auditory canal (EAC), also known as meatus acusticus externus or external acoustic meatus, is an $S$ shaped osseo-cartilaginous structure that extends from the auricle to the tympanic membrane being about $4 \mathrm{~cm}$ in length if measured from the tragus. The lateral one-third of this structure is cartilaginous while the medial two-third is bony tissue [1]. The main function of the EAC is to conduct sound waves in the form of vibrations collected by the auricle up to the eardrum.

Different types of lesions affecting the EAC can be clinically diagnosed: congenital (atresia), inflammatory (malignant otitis externa and osteomyelitis), and neoplastic (bone tumors). Moreover, trauma and miscellaneous conditions, such as squamous epithelium growth, known as cholesteatoma, also affect the EAC [2]. The conventional techniques for surgical treatment of chronic inflammatory processes in the middle ear are the closed, namely, intact canal wall up (CWU), and open, namely, canal wall down (CWD) tympanoplasty [3]. The benefits and pitfalls of CWU, CWD and CWD with mastoid obliteration and canal wall reconstruction techniques are widely described in literature [3, 4]. However, the choice of technique depends on specific factors related to the surgeon expertise, patient typology and disease process [4]. Techniques including reconstruction of EAC wall involve partial or complete removal of the posterior bone wall of the meatus and the reconstruction of this structure after elimination of a pathological process.

Different reconstructive methods of the posterior wall of the EAC and its removal have been reported in a distinguished review article [3]. The first studies performed in the late fifties described the reconstruction procedure by using autologous iliac crest bone and homograft septal cartilage. Thereafter, many types of biologic tissue grafts have been proposed, such as tympanic canal homograft, muscle-periosteum-bone flap, banked femoral head fragments, and autologous mastoid bone powder [3]. In 1979, Wullstein and coworkers pioneered the implant of synthetic biomaterials for the reconstruction of the posterior bone wall, which paved the way to the use of polymers (Proplast $^{\circledR}$, Plastipore ${ }^{\mathrm{TM}}$ ), ceramics and glass ceramics (Ceravital $^{\circledR}$, hydroxylapatite, Corail ${ }^{\circledR}$ and ionomers), as well as metals (titanium) [5]. However, beside great efforts in otologic surgery, the current biomaterial-based approaches still suffer from either resorption using biological materials or extrusion using synthetic materials, thus highlighting the unmet need for a reliable substitute in this body setting [6]. The dismal fate of biomaterials in the ear seems to be a consequence of the permanently inflamed and contaminated environment, subject to vibratory movement in the case of neighboring eardrum and ossicles, even exacerbated by the changes in ventilation systems induced by surgery [7]. A recently proposed approach relies on the application of tissue engineering (TE) strategies in otology, and proof of concept approaches have been proposed for the ossicular chain and tympanic membrane reconstruction by in vitro culturing scaffolds provided with a specific shape with human mesenchymal stem cells (hMSCs) [8-11]. These studies turned out into very good results in terms of viability and extracellular matrix (ECM) deposition by differentiated cells. Differently from other TE applications, otologic TE must take into great account the specific shape and size of the different tissues present in the outer and middle ear, since they are key enabling factors for sound conducting process through a precise anatomy reconstruction.

Among the conventional additive manufacturing techniques, Fused Deposition Modeling (FDM) is one of the commonly used for the production of scaffolds for hard 
tissue replacement due to the possibility to produce these types of structures with customized mechanical properties $[12,13]$. Moreover, it is possible to produce custom-made scaffolds with specific shapes and accurate size from computer-aided design (CAD) models obtained from the patients by magnetic resonance imaging or computer tomography techniques. Three-dimensional (3D) fiber deposition (3DF) is a type of FDM technique that has been extensively studied for the production of scaffolds for diverse TE applications, including bone, cartilage, osteochondral defects, and trachea [14-18].

To provide a TE solution for EAC surgery, in this study 3DF scaffolds based on poly(ethylene oxide terephthalate)/ poly(butylene terephthalate) (PEOT/PBT) copolymer were designed and fabricated to replace the EAC wall. Fiber size and scaffold porosity were optimized to obtain a suitable scaffold for this application, and its mechanical properties were evaluated. Finally, the EAC scaffolds were tested in vitro with osteoinduced hMSCs by using different seeding methods to achieve homogeneously colonized replacements of interest for otologic surgery. This work aims at proposing third generation biomaterials approach, namely, the use of scaffolds to replace EAC wall, thus opening the way for a TE scenario to this and other otologic applications.

\section{Materials and methods}

\subsection{Materials}

PEOT/PBT was provided by PolyVation BV (Groningen, The Netherlands). The commercial designation of this random block copolymer follows an aPEOTbPBTc nomenclature, where "a" is the molecular weight $\left(\mathrm{Mw}, \mathrm{g} \mathrm{mol}^{-1}\right)$ of the poly(ethylene oxide) (PEO), "b" and "c" represent the weight ratios of PEOT and PBT, respectively. The block copolymer used in this study was 300PEOT55PBT45. Lowglucose $\left(1000 \mathrm{mg} \mathrm{L}^{-1}\right)$, Minimum Essential Medium Eagle -Alpha Modification (Alpha MEM), L-glutamine, penicillin-streptomycin (Pen-Strep), fungizone, trypsin, phosphate buffered saline (PBS), gelatin (Type B, 75 Bloom, from bovine skin), $\beta$-glycerophosphate, ascorbic acid, dexamethasone, Triton-X-100, neutral red, trypan blue, Mayer's hematoxylin solution, Eosin B, DPX mounting medium, absolute silver nitrate, pyrogallol, sodium thiosulfate, nuclear fast red, aluminum sulfate, ethanol, xylene, and methanol were provided by SigmaAldrich (Milan, Italy). Heat-inactivated fetal bovine serum (FBS), AlamarBlue ${ }^{\circledR}$ and paraffin histoplast LP from Thermo Fisher Scientific (Waltham, MA, USA). Lymphoprep was supplied by Axis-Shield, Norway. Calcium chloride for human use was purchased from Bioindustria
Farmaceutici (Rome, Italy). EAC wall prosthesis TPL 07.39, was kindly supplied by Audiotechnologies (Gossolengo, PC, Italy). All the products were used as received, if not otherwise specified in the methods section.

\subsection{Scaffold design}

The outer shape of EAC wall was designed according to a commercially available bulk prosthesis made of hydroxylapatite (TPL 07.39) and in accordance with surgeons' advices. The 3D modeling of the EAC was performed by implementing the following steps: (1) accurate measure of the features and geometry of commercial samples using a digital caliper and micrometer (Mitutoyo Corp., Tokyo, Japan) and reference structures (planar ruler, precision set square), and (2) generation with SolidWorks software (Dassault Systemes, France) of a 3D CAD model. For the generation of the 3D model, a portion of hollow ellipsoid matching the overall size of the sample was generated and further steps were performed: (2.1) deformation of the primitive to match the geometry of the sample; (2.2) 3D cutting of concave features as in the sample, and (2.3) filleting of edges with appropriate curvature radii. Two cycles of iteration of the above mentioned steps were performed to verify the congruence of the 3D model and the physic sample.

\subsection{Scaffold manufacturing}

A first prototype of the EAC wall was manufactured in bulk polymer $\left(\right.$ Delrin $\left.^{\circledR}\right)$ with a computer numerically controlled machine (CnC 4 Axis, Esanastri, Calcinaia, Pisa, Italy) equipped with dremel (1050 FME, KRESS-elektrik GmbH \& Co. KG, Bisingen, Germany).

The fabrication of the porous EAC scaffold was performed via 3DF deposition technique using 3D-Bioplotter $^{\mathrm{TM}}$ (EnvisionTEC GmbH, Germany). The functioning principle of this equipment is FDM assisted by nitrogen $\left(\mathrm{N}_{2}\right)$ gas pressure to promote the extrusion of a molten polymer. The parameters that specifically influence the production of the $3 \mathrm{D}$ scaffolds are: temperature, $\mathrm{N}_{2}$ pressure, deposition velocity and extrusion nozzle diameter. A detailed description of the system has been reported by Moroni et al. [15, 19]. Briefly, the system is composed of a stainless steel syringe were the PEOT/PBT was loaded and heated at a temperature of $205^{\circ} \mathrm{C}$. After obtaining the complete polymer melting, $\mathrm{N}_{2}$ pressure was applied at 5 bar, while an electrovalve controlled the extrusion of the polymer. For the fabrication of the EAC wall scaffold, two nozzles with different internal diameters (I.D.) were used, namely, G25 (I.D. $=250 \mu \mathrm{m}$ ) and G27 (I.D. $=200 \mu \mathrm{m}$ ). The deposition velocity was optimized and varied from 56 to $196 \mathrm{~mm} \mathrm{~min}^{-1}$. The 3D models of the EAC wall scaffold 
Table 1 3DF scaffold geometrical properties and optimized processing parameters

\begin{tabular}{|c|c|c|c|c|c|c|c|c|c|}
\hline \multirow{2}{*}{$\begin{array}{l}\text { Gauge (I.D.) } \\
(\mu \mathrm{m})\end{array}$} & \multirow{2}{*}{$\begin{array}{l}\mathrm{V}_{\mathrm{dep}} \\
(\mathrm{mm} / \\
\mathrm{min})\end{array}$} & \multirow[t]{2}{*}{ P (bar) } & \multirow[t]{2}{*}{$\mathrm{T}\left({ }^{\circ} \mathrm{C}\right)$} & \multicolumn{2}{|c|}{ Designed } & \multicolumn{3}{|l|}{ Obtained } & \multirow[t]{2}{*}{ Porosity (\%) } \\
\hline & & & & $\mathrm{d}_{2}(\mu \mathrm{m})$ & $\mathrm{d}_{3}(\mu \mathrm{m})$ & $\mathrm{d}_{1}(\mu \mathrm{m})$ & $\mathrm{d}_{2}(\mu \mathrm{m})$ & $\mathrm{d}_{3}(\mu \mathrm{m})$ & \\
\hline G25 (250) & 196 & 5 & 200 & 400 & 175 & $293 \pm 27$ & $410 \pm 24$ & $152 \pm 65$ & $28 \pm 10$ \\
\hline G27 (200) & 56 & 5 & 200 & 400 & 150 & $200 \pm 33$ & $402 \pm 33$ & $150 \pm 12$ & $55 \pm 5$ \\
\hline
\end{tabular}

The $d_{1}, d_{2}$, and $d_{3}$ values were measured $(n=20)$ with ImageJ software on SEM images from the top-view and cross section of the produced scaffolds. The obtained values for $d_{1}, d_{2}, d_{3}$ and scaffold porosity are reported as mean \pm standard deviation $(\mathrm{SD})$ were uploaded into the equipment using PrimCAM software (Primus Data, Switzerland) and the deposition patterns were calculated. The fiber diameter $\left(d_{1}\right)$ obtained varied according to the nozzle diameter used. The fiber spacing $\left(d_{2}\right)$, defined as the distance between successive fibers in the same layer, ranged in 300-600 $\mu \mathrm{m}$ and the layer thickness $\left(d_{3}\right)$ ranged between 150 and $175 \mu \mathrm{m}$. The scaffold was built layer upon layer with a $0-90^{\circ}$ architecture, and the fibers were deposited with a $90^{\circ}$ step between successive layers. The design and manufacturing parameters for the produced scaffold are resumed in Table 1.

Plasma treatment is a technique that allows the improvement of cell adhesion by changing surface roughness [20]. All the produced scaffolds were treated with Argon (Ar) plasma. Scaffolds were placed inside the radiofrequency glow-discharge chamber (Harrick Scientific Corp., NY, USA). A pre-vacuum was applied until a 0.01 mbar pressure was reached; a subsequent flush with $\mathrm{Ar}$ gas was applied for four times. The treatment was performed for $30 \mathrm{~min}$ at a controlled vacuum ranging in 0.1-0.2 mbar with high settings applied to the radiofrequency coil (740 V DC, $40 \mathrm{~mA} \mathrm{DC}, 29.6 \mathrm{~W})$.

\subsection{Scaffold characterization}

\subsubsection{Scaffold morphology and porosity}

Scaffold architecture and fiber morphology were analyzed via scanning electron microscopy (SEM; Phillips XL30 ESEM-FEG). The samples were sputter-coated with gold (Cressington, Watford, England) for $60 \mathrm{~s}$ prior to SEM analysis. SEM micrographs were acquired from the top and cross-section of the scaffolds at different magnifications. The $\mathrm{d}_{1}, \mathrm{~d}_{2}$, and $\mathrm{d}_{3}$ values were measured $(n=20)$ with ImageJ software on SEM images from the top-view and cross section of the produced scaffolds. Gravimetric porosity EAC scaffold was assessed via liquid pycnometry ( $n$ $=3$ ), according to the following equation:

$$
\text { Porosity }=\left(1-\frac{M}{V} \times \frac{1}{\rho}\right) \times 100 \% \text {, }
$$

where $M$ and $V$ are the mass (as weighted) and volume (as from the 3D CAD model) of the scaffolds and $\rho$ is the density of the copolymer (300PEOT55PBT45), which equals to $1.2 \mathrm{~g} \mathrm{~cm}^{-3}$.

The best EAC scaffold type, selected according to the analyses listed above (i.e., G27 type), underwent an extended characterization, including X-ray micro computed tomography (micro-CT) scan and compressive mechanical tests. Volumetric porosity and other dimensional features, such as connectivity, surface/volume, and local thickness $[21,22]$ of the EAC scaffold were obtained via X-ray micro-CT, using XALT scanner (namely, "X-ray AnimaL Tomograph" built at the CNR of Pisa) [23] with the following scan settings: $50 \mathrm{kVp}, 2.5 \mathrm{~mm} \mathrm{Al}, 0.5 \mathrm{~mA}, 640$ projections over $360^{\circ}, 1.1 \mathrm{~s} /$ projection and a spatial resolution of $18.4 \mu \mathrm{m}$. Volumetric images were reconstructed using a modified cone-beam filtered-back projection algorithm on a matrix of $850 \times 850 \times 1000$ voxels, with isotropic voxel size of $25.3 \mu \mathrm{m}$. Images were then segmented and quantitatively analyzed with the BoneJ plugin of the ImageJ software $[24,25]$. Using the trabecular analysis package of BoneJ and treating the scaffold fibers as trabeculae, the following morphological parameters of the EAC scaffold were analyzed: total volume (TV), volume fraction occupied by the material (BV/TV), surface/volume ratio (BS/ BV), local thickness (Tb.Th), connectivity and connectivity density (Conn and Conn.D).

\subsubsection{Mechanical properties of the scaffold}

Compression tests were performed on cylindrical specimens with the highest porosity pattern G27 $(n=3)$. 3D fiber deposited samples in the form of cylinders were fabricated with the following dimensions to avoid significant effects deriving from friction forces [26]: $12.55 \mathrm{~mm}$ diameter (D) $\times$ $25 \mathrm{~mm}$ length (L), which lead to $\mathrm{L} / \mathrm{D} \geq 1.5$. Each sample was tested using an Instron machine 4464 with a loading cell of $1 \mathrm{kN}$ under 10 repetitions. Two plates made of aluminum were used to compress the samples with a constant velocity of $1 \mathrm{~mm} \mathrm{~min}^{-1}$.

Outcomes of the test, namely, applied force $(F)$ and shortening $\left(\Delta L=L_{0}-L\right)$, were acquired by a dedicated software (LabVIEW ${ }^{\mathrm{TM}}$, National Instruments) and statistically analyzed through Microsoft Excel (Windows Office 2010). To evaluate the compressive modulus (E), applied 
force and shortening data were recorded to calculate both stress $(\sigma)$ and deformation $(\varepsilon)$ :

$\sigma=\frac{F}{A_{0}}$

$\varepsilon=\frac{\Delta L}{L_{0}}$

where $A_{0}$ and $L_{0}$ are sample initial cross section and length, respectively.

For each repetition, a study of the $\sigma-\varepsilon$ curve was carried out to determine the first linear part. Once identified, the compressive modulus was calculated as the slope of the linear region. A descriptive statistical analysis of the quantitative data were presented as mean \pm standard deviation (SD).

\subsection{In vitro study}

\subsubsection{Ethical statement}

HMSCs were obtained from bone marrow aspirates of patients admitted to Pisa hospital for orthopedic surgery. Human plasma was obtained by collecting leftovers from routinely blood tests in our hospital. Samples were collected after informed consent, treated anonymously and in conformity to the principles expressed by the Declaration of Helsinki.

\subsubsection{Isolation and culture of hMSCs}

HMSC cultures were established as reported in our previous studies [27]. Briefly, the aspirate was diluted 1:3 in sterile saline and layered on Lymphoprep density gradient. After centrifugation at $400 \times g$ for $25 \mathrm{~min}$, the mononuclear cell layer formed, which was taken out and suspended in culture medium (CM), consisting of Alpha MEM, 2 mM L-glutamine, $100 \mathrm{IU} \mathrm{mL} \mathrm{mL}^{-1}$ penicillin, $100 \mathrm{mg} \mathrm{mL}^{-1}$ streptomycin and $10 \%$ (v\%) fetal bovine serum (FBS). The mononuclear cells were suspended in CM were counted with a hemocytometer using trypan blue to check their viability, and finally cells at a density of $0.2 \times 10^{5}$ viable cells per $\mathrm{cm}^{2}$ were plated in tissue culture polystyrene flasks. After $24 \mathrm{~h}$, non-adherent cells were washed away from the cultures using sterile saline and fresh CM was added to the adherent cells. When the cultures reached about $70-80 \%$ confluence, the adherent cells (i.e., the purified hMSCs) were detached using $0.25 \%$ trypsin, replated at a cell density of $10^{3}$ cells/ $\mathrm{cm}^{2}$ and expanded in regular CM until $70 \%$ confluence.

\subsubsection{Culture and differentiation of hMSC/EAC wall scaffold constructs}

EAC wall scaffolds $(n=3)$ were sterilized with absolute ethanol overnight and washed with PBS containing $3 \mathrm{X}$ pen- strep and fungizone three times for $10 \mathrm{~min}$. Due to the large scaffold size, $12 \times 10^{6}$ cells were seeded in each sample to obtain a complete cell colonization. To ensure a uniform seeding, the following three strategies were performed which availed themselves of multiple seeding shots $(20 \mu \mathrm{L}$ each) with cells suspended either in gelatin (filtered $2 \%$ aqueous solution) or in human pooled plasma, the latter crosslinked using a $7 \mathrm{mM}$ calcium chloride solution $(0.4 \mu \mathrm{L}$ per $\mu \mathrm{L}$ of plasma) for $20 \mathrm{~min}$ [27]:

(1) hMSC/gelatin suspension: $4 \times 10^{6}$ cells (day 1$)+6 \times$ $10^{6}$ cells (day 6$)+2 \times 10^{6}$ cells (day 12 );

(2) hMSC/gelatin suspension: $4 \times 10^{6}$ cells (day 1$)+8 \times$ $10^{6}$ cells (day 9);

(3) hMSC/plasma suspension: $4 \times 10^{6}$ cells (day 1$)+6 \times$ $10^{6}$ cells (day 6$)+2 \times 10^{6}$ cells (day 12 ).

Different seeding times were needed for a proper hMSC expansion, thus reaching the necessary cell numbers. To monitor cell localization in the scaffold, before reseeding times, the alamarBlue ${ }^{\circledR}$ test was qualitatively performed following the manufacturer's recommendations and an incubation time of $3 \mathrm{~h}$. The slight pink-orange color retained by the construct after CM removal allowed empty areas of the scaffolds to be detected and thus seeded for an optimal cell colonization. Stained constructs were photographed with digital camera (Canon Digital Ixus 50). After completion of the seeding process, hMSC/scaffold constructs were differentiated for further 21 days using osteogenic CM, consisting of Alpha MEM supplemented with $10 \%$ FBS, $2 \mathrm{mM}$ L-glutamine, 100 U.I. $\mathrm{mL}^{-1}$ penicillin, $100 \mu \mathrm{g}$ $\mathrm{mL}^{-1}$ streptomycin, $1 \mu \mathrm{g} \mathrm{mL}^{-1}$ fungizone, with differentiating factors $0.1 \mu \mathrm{M}$ dexamethasone, $10 \mathrm{mM} \beta$-glycerophosphate and $50 \mu \mathrm{g} \mathrm{mL}^{-1}$ ascorbic acid. Cell cultures were carried out in incubator under standard conditions (namely, $37{ }^{\circ} \mathrm{C}, 95 \%$ relative humidity, and $5 \% \mathrm{CO}_{2} / 95 \%$ air environment). At the endpoint, cell viability was qualitatively assessed by means of the Neutral Red assay. Briefly, the constructs were incubated with $50 \mathrm{mg} \mathrm{mL}^{-1}$ of the dye in CM for $3 \mathrm{~h}$, rinsed in sterile PBS and observed under an inverted light microscope (Nikon Ti-E, Nikon Instruments, Tokyo, Japan). At the endpoint, the constructs were fixed with formalin overnight and processed for SEM and histologic analyses.

\subsubsection{Biological characterization}

After fixation and dehydration, the hMSC/scaffold constructs were sectioned with scissors. One piece per type was sputter-coated with gold and observed under SEM to evaluate cell colonization and presence of ECM molecules. The residual parts of the samples were processed for histochemical analysis. Hematoxylin-eosin (H\&E) staining was used to analyze cell morphology and scaffold colonization 
Fig. 1 EAC prosthesis: a 3D

CAD model design by means of

SolidWorks software, b

polymeric bulk prototype, $\mathbf{c}, \mathbf{d}$

EAC scaffolds produced by

means of 3DF technique with

different nozzles: c gauge 25 (I.

D. $=250 \mu \mathrm{m})$, and $\mathbf{d}$ gauge 27

(I.D. $=200 \mu \mathrm{m}$ )
A
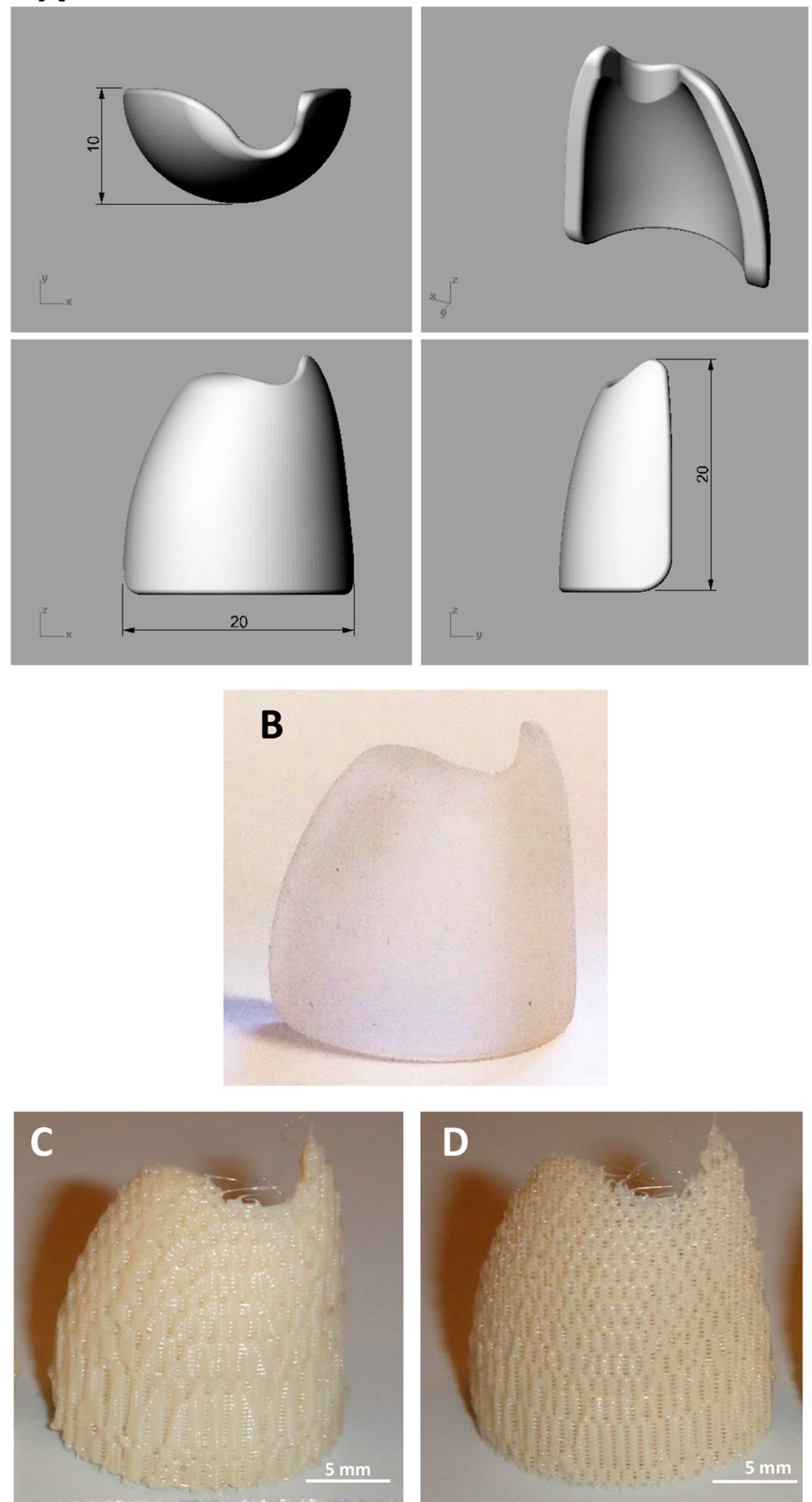

following the standard anatomic-pathology protocol. Mineral matrix deposition was evaluated by von Kossa staining. For this analysis, the sections were incubated in
$1 \%$ silver nitrate for $15 \mathrm{~min}$ in the light, in $0.5 \%$ pyrogallole for $2 \mathrm{~min}$ and in 5\% sodium thiosulfate for $2 \mathrm{~min}$. Finally, the specimens were counterstained in $0.1 \%$ nuclear fast red 
diluted in 5\% aluminum sulfate solution for $5 \mathrm{~min}$ and revealed in tap water for $5 \mathrm{~min}$. The sections were observed with a Nikon Eclipse Ci microscope (Nikon Instruments, Amsterdam, The Netherlands) equipped with a digital camera.

\section{Results}

\subsection{Fabrication and characterization EAC wall scaffolds}

The production of the EAC wall scaffolds was performed with the optimized parameters described in the previous section. The overall dimensions of the CAD model were $10 \times 20 \times 20 \mathrm{~mm}^{3}$ (Fig. 1a). A solid 3D model was generated (Fig. 1a) which allowed a dimension comparison with the bulk polymer counterpart produced by CNC micromilling (Fig. 1b). Owing to the complexity of the geometry and the reduced thickness, some irregularities on the prepared scaffolds were observed. The achieved accuracy, as measured with a micrometer (Mitutoyo, Tokyo, Japan), was less than $0.1 \mathrm{~mm}$.

3DF deposition was therefore used to produce porous EAC wall scaffolds using two different I.D. nozzles, namely, G25 (I.D. $=250 \mu \mathrm{m}$ ) and G27 (I.D. $=200 \mu \mathrm{m}$ ). The lack of structural support when the fibers were deposited outside the limits of the previously built layers, sometimes hampered an accurate resolution; however, satisfactory scaffolds were produced (Fig. 1c, d). The EAC scaffold porosity was calculated according to the Equation 1 , considering the volume of the scaffold obtained from the
3D CAD model. A gravimetric porosity of $28 \% \pm 10 \%$ was achieved with G25 nozzle. The values obtained for $d_{1}, d_{2}$ and $d_{3}$ with the optimized processing parameters were 293 $\pm 27,410 \pm 24$ and $152 \pm 65 \mu \mathrm{m}$, respectively (Table 1). The compact texture of this scaffold was confirmed by SEM observation (Fig. 2a, b). Indeed, the fibers were tightly connected, especially on the scaffold outer surface, thus resulting in low pore volume and poor pore interconnectivity. Due to the small scaffold thickness, an accumulation of polymer on the pattern limits caused the fusion of the layers observed in Fig. 2 A1. Moreover, no porosity was observed on the external surface limiting the pore interconnectivity (Fig. 2 A2). Furthermore, the obtained $d_{3}$ was lower and with a large standard deviation when compared to the designed value. This was probably attributed to the low heat dissipation and slow polymer quenching while the scaffold was being printed inducing a further compaction of the scaffold in $\mathrm{Z}$ direction.

Improved pore interconnectivity and porosity was achieved by using a nozzle with a smaller diameter (G27) (Fig. 2b). In this case, a porosity of $55 \% \pm 5 \%$ was obtained. The values of $d_{1}, d_{2}$ and $d_{3}$ were $200 \pm 33 \mu \mathrm{m}$, $402 \pm 33 \mu \mathrm{m}$ and $150 \pm 12 \mu \mathrm{m}$, respectively (Table 1). However, the smaller the nozzle size, the higher the fabrication time of each EAC scaffold, which turned into a significantly slow fabrication rate. After optimization with a smaller nozzle diameter, completely open porosity was obtained which could be observed both on scaffold crosssection and external surfaces (Fig. 2 B1, B2). The EAC wall scaffold produced using G27 was therefore chosen for subsequent micro-CT, mechanical and biological characterizations.
Fig. 2 SEM micrographs of EAC wall scaffolds produced by means of 3DF technique with a G25 and b G27: (A1, B1) cross sections and (A2, B2) outer surfaces
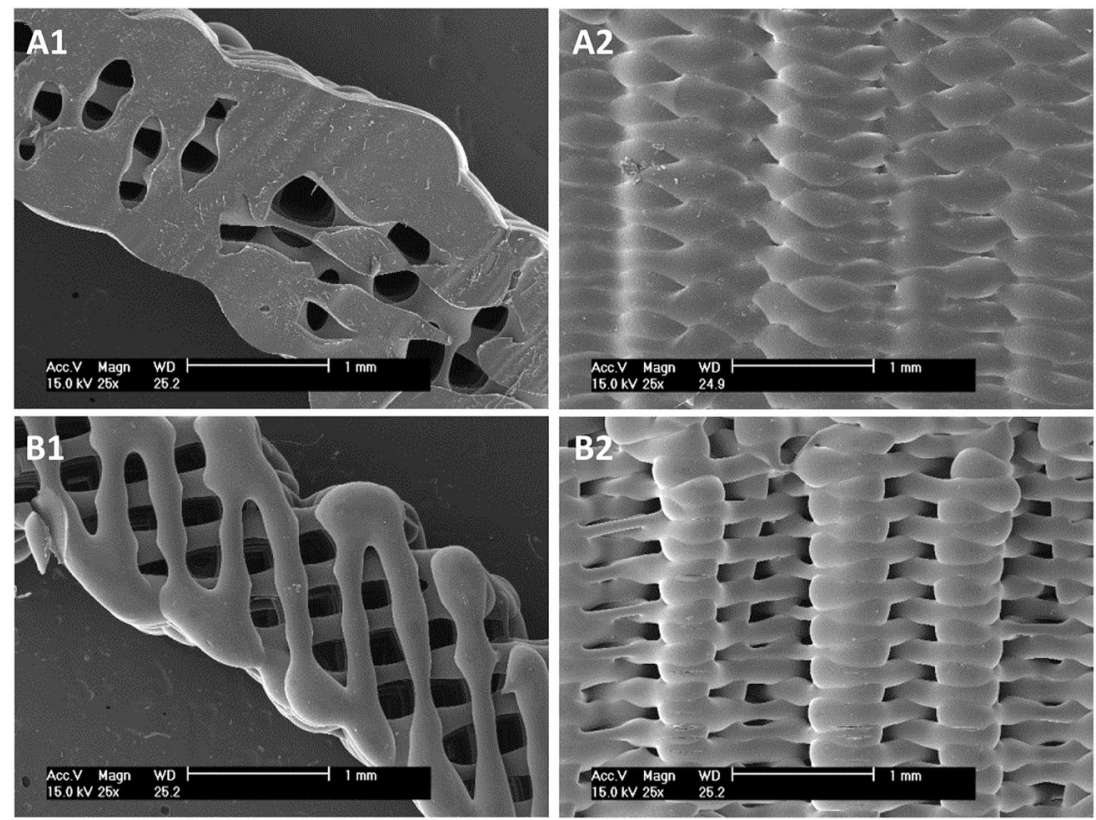
Fig. 3 Results of micro-CT analysis: a $3 \mathrm{D}$ reconstruction, $\mathbf{b}$ bulk EAC device, $\mathbf{c}$ porous EAC scaffold (produced with gauge G27). Pictures show both (A1, $\mathrm{B} 1, \mathrm{C} 1)$ convex, and (A2, B2, $\mathrm{C} 2$ ) concave sides of the scaffold. B3 and C3 are representative cross sections of bulk the device and the scaffold, respectively
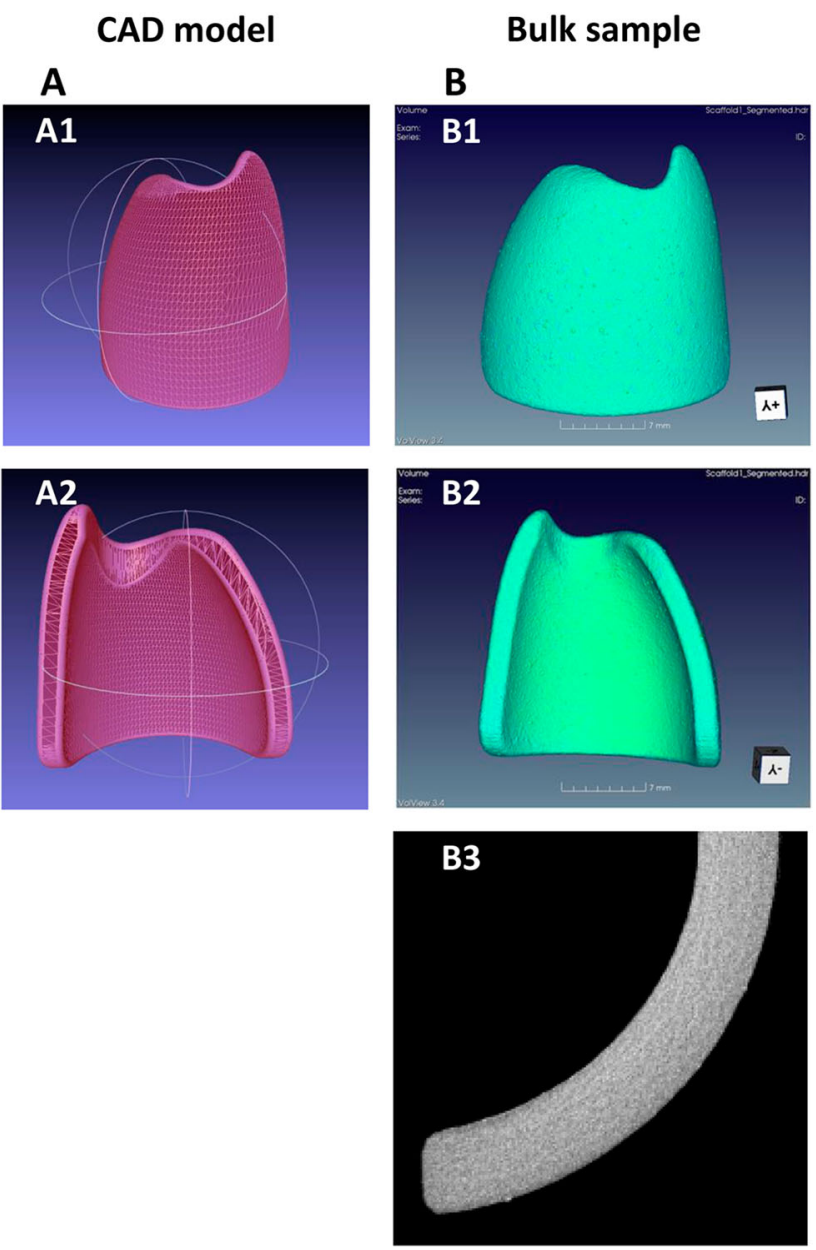
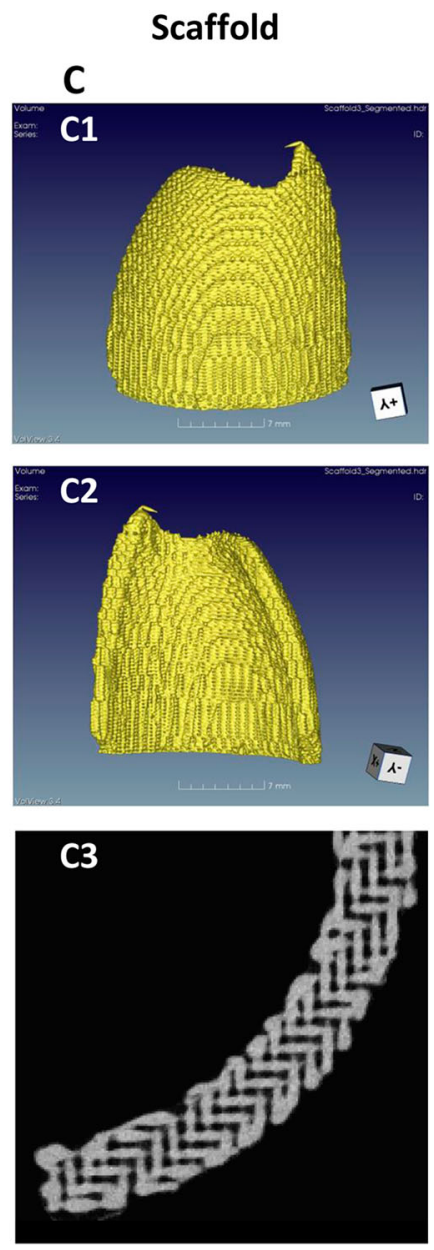

Table 2 Micro-CT parameters related to the EAC scaffold obtained with gauge G27

\begin{tabular}{|c|c|c|c|c|}
\hline Parameter & Unit & $\begin{array}{l}\text { Bulk } \\
\text { device }\end{array}$ & $\begin{array}{l}\text { EAC } \\
\text { scaffold }\end{array}$ & $\begin{array}{l}\text { CAD } \\
\text { model }\end{array}$ \\
\hline Mass & $\mathrm{mg}$ & 1080.4 & 694.8 & - \\
\hline Bulk volume & $\mathrm{mm}^{3}$ & 947 & 764 & 898 \\
\hline Volume & $\mathrm{mm}^{3}$ & 947 & 462 & - \\
\hline Volume/bulk volume & - & 1 & 0.605 & - \\
\hline Relative density (bulk) & $\mathrm{mg} \mathrm{mm}^{-3}$ & 1.141 & 0.909 & - \\
\hline Relative density & $\mathrm{mg} \mathrm{mm}^{-3}$ & 1.141 & 1.504 & - \\
\hline Surface & $\mathrm{mm}^{2}$ & 1177 & 4398 & 1040 \\
\hline Surface/volume & $\mathrm{mm}^{-1}$ & 1.243 & 9.519 & 1.158 \\
\hline External thickness (mean) & $\mathrm{mm}$ & 2.030 & 1.719 & - \\
\hline External thickness (SD) & $\mathrm{mm}$ & 0.129 & 0.232 & - \\
\hline External thickness (max) & $\mathrm{mm}$ & 2.110 & 1.991 & - \\
\hline Local thickness (mean) & $\mathrm{mm}$ & 2.030 & 0.294 & - \\
\hline Local thickness (SD) & $\mathrm{mm}$ & 0.129 & 0.130 & - \\
\hline Local thickness (max) & $\mathrm{mm}$ & 2.110 & 0.943 & - \\
\hline Connectivity $^{\mathrm{a}}$ & - & 0 & 16173 & 0 \\
\hline Connectivity density & $\mathrm{mm}^{-3}$ & 0 & 21.169 & 0 \\
\hline
\end{tabular}

${ }^{\mathrm{a} C o n n e c t i v i t y ~ w a s ~ d e f i n e d ~ a s ~ i n ~[24] ~}$
3D reconstructions of bulk and porous G27 EAC scaffolds obtained via micro-CT analysis are shown in Fig. 3. MicroCT quantitative analysis showed a local thickness of the fibers of $294 \pm 130 \mu \mathrm{m}$ (Tb.Th mean \pm SD), with a volume fraction occupied by the fibers of $60 \%(\mathrm{BV} / \mathrm{TV})$ and a surface/volume ratio of $9.52 \mathrm{~mm}^{-1}$ (BS/BV) (Table 2). The connectivity density was $21.2 \mathrm{~mm}^{-3}$ (Conn.D). Cross section indeed showed highly interconnected pores (Fig. 3C3).

The mechanical characterization aimed at calculating the Young's modulus of the scaffold through compression tests on samples with standardized dimensions (Fig. 4a). A representative $\sigma-\varepsilon$ curve of the compression test is shown in Fig. 4b. The compressive Young's modulus, calculated from the linear region of the $\sigma-\varepsilon$ curve was $25.1 \pm 7.0 \mathrm{MPa}$. Good deformation of the EAC shaped scaffolds is supportive for surgical handling during implantation (Supplementary video $\mathrm{S} 1$ ).

\subsection{Characterization of hMSC/EAC wall scaffold constructs}

AlamarBlue $^{\circledR}$ as a non-disruptive assay was qualitatively performed to visualize cell colonization before each 
Fig. 4 Outcome of mechanical test performed on EAC wall scaffolds (G27) under compressive mode: a test samples with representative dimensions and texture (lens), and $\mathbf{b}$ the obtained stress-strain curve, showing the linear part in orange
A
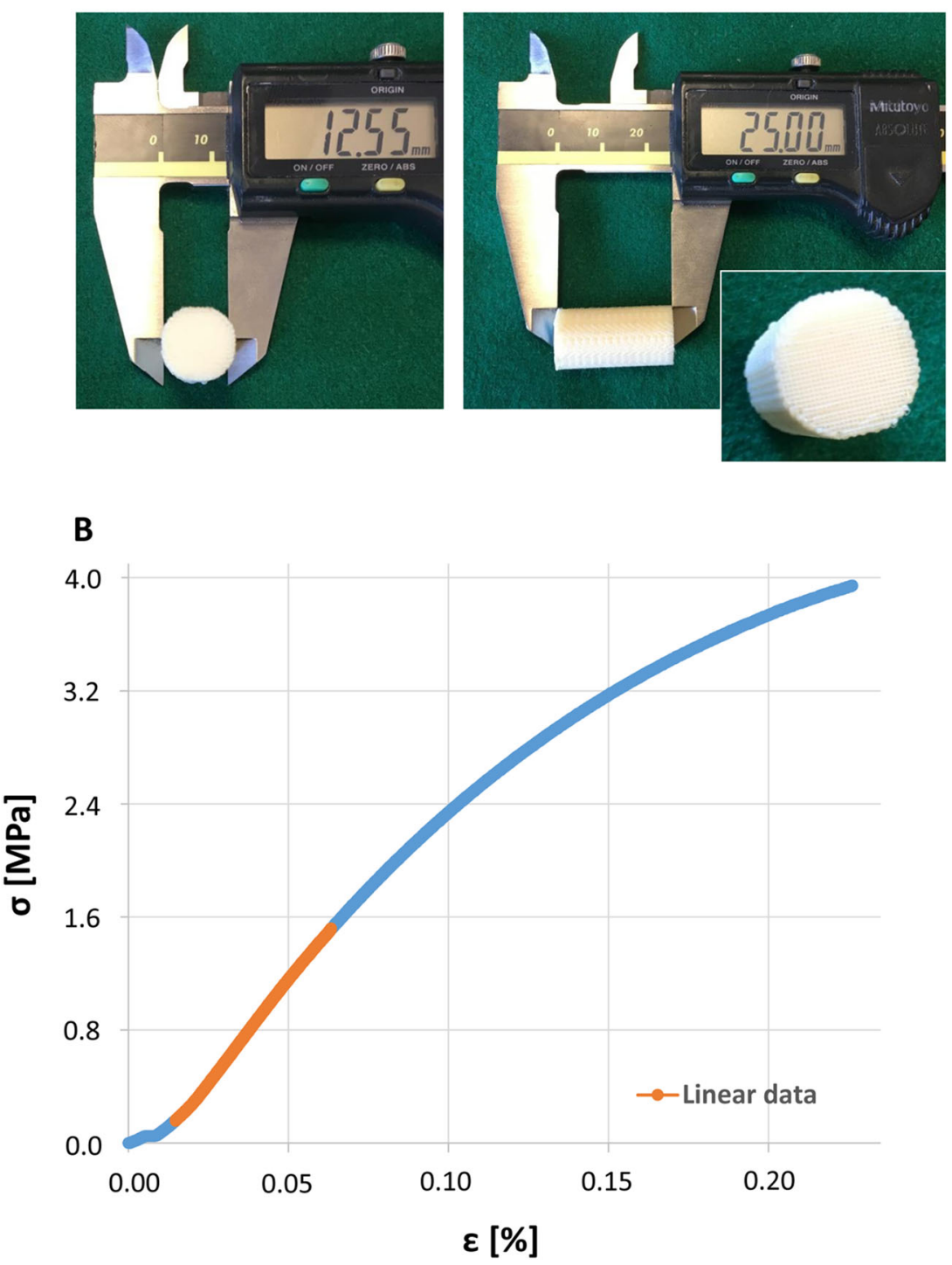

subsequent seeding step, aimed at obtaining homogeneously colonized scaffolds before osteoinduction. Due to a metabolic reaction, alamarBlue ${ }^{\circledR}$ turns from blue to pink in presence of live cells. Although the reaction affects the $\mathrm{CM}$, after CM removal, the pink color is still visible in $3 \mathrm{D}$ cultures as some CM is locally retained by the scaffold surrounding the metabolically active cells. As a representative example, Fig. 5 shows hMSC colonization in an EAC wall construct seeded according to the strategy "a". Constructs stained with alamarBlue ${ }^{\circledR}$ on day 6 and 12 showed some areas with low color intensity, which were therefore addressed during the following seeding step (Fig. $5 \mathrm{a}, \mathrm{b})$. It can be observed that on day 12 , color intensity increased and color spatial distribution was improved with respect to those on day 6 , which is suggestive of enhanced cell viability and distribution (Fig. 5a, b). In this way, all the constructs seeded according to the three strategies appeared homogeneously colonized before initiating osteogenic differentiation. The presence of live cells at the endpoint was assessed using Neutral Red assay, which showed scaffold pores filled with viable and well stretched out cells (Fig. 5c).

The surfaces of osteodifferentiated constructs were analyzed via SEM, which confirmed a good spatial colonization of the EAC wall scaffolds seeded with the three strategies (Fig. 6a-c). In all the samples, cells and ECM molecules (Fig. 6a-c, lens) were observed. No significant difference could be noticed among the constructs seeded with three different strategies.

Finally, histological analysis was performed to investigate in detail cell morphology, cell-scaffold interaction and mineral matrix production. H\&E staining highlighted cells with round morphology typical of mature osteoblasts which were both in tight contact with the scaffold fibers and filling 
Fig. 5 Qualitative viability staining showing cell colonization on an EAC wall scaffold seeded with the strategy "a", namely, hMSCs suspended in gelatin and seeded in 3 steps: a, b photographs of alamarBlue ${ }^{\circledR}$ stained construct on day 6 (a) and day 12 (b); c micrographs of Neutral Red stained constructs at the endpoint. Pictures show both (A1, B1, C1) concave and (A2, $\mathrm{B} 2, \mathrm{C} 2$ ) convex sides of the scaffold
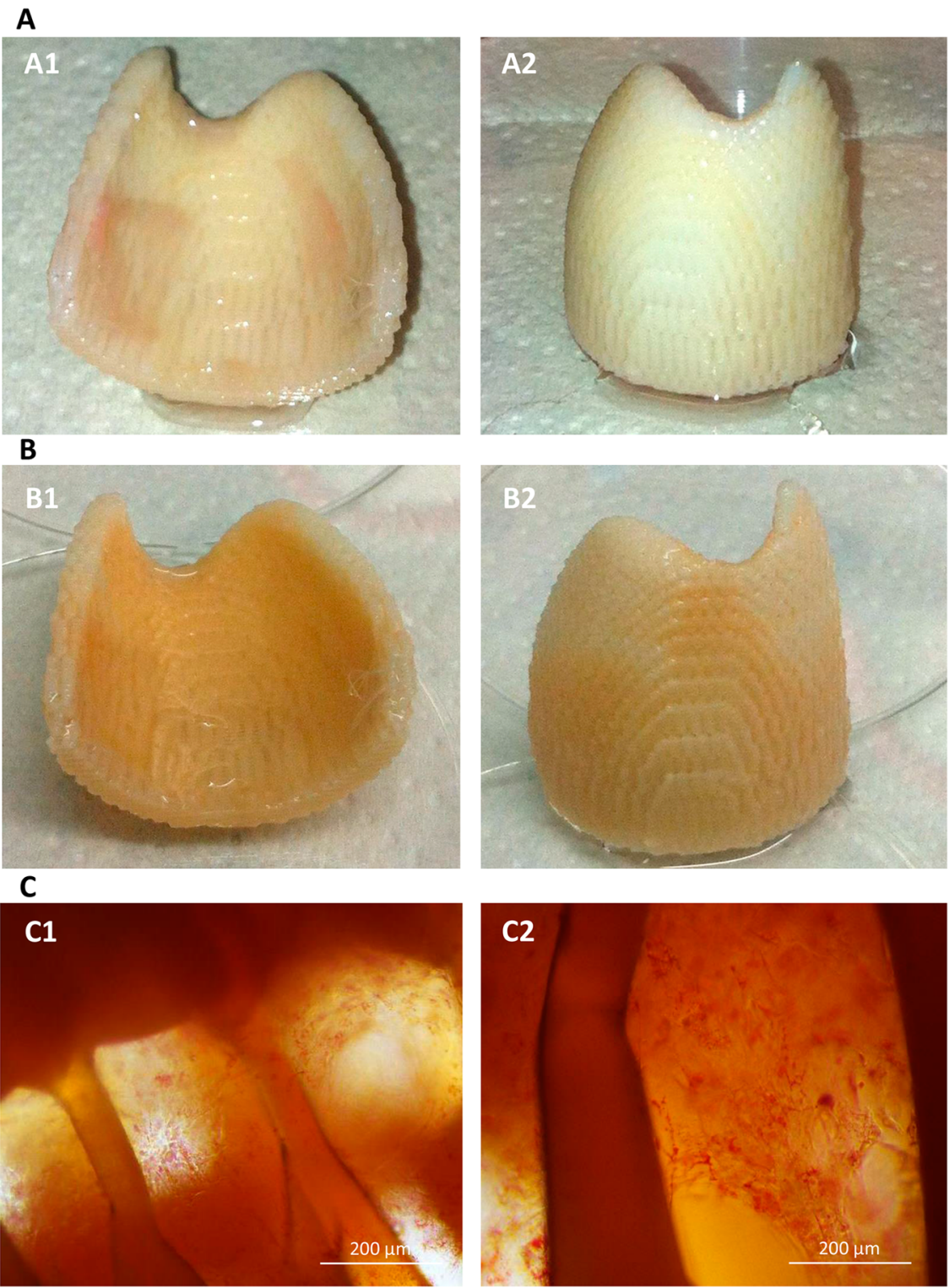

the inter-fiber porosity (Fig. 7a). Von Kossa staining showed large production of mineral granules (in black), in presence of cells (in red), which corroborated the hMSC osteodifferentiation in all the samples, with no relevant difference attributable to seeding strategies (Fig. 7b).

\section{Discussion}

This study focused on the fabrication and characterization of EAC wall scaffolds via 3DF, as an additive manufacturing technique, to enable future devices for EAC reconstruction under the TE paradigm, in which third generation biomaterials in the form of scaffolds interact with the specific microenvironment and ultimately lead to the functional restoration of the injured tissue.
The first generation biomaterials, also known as bioinert, date back to the fifties and had the purpose to create of-theshelf devices with suitable physical properties to permanently replace a tissue without any detrimental host response. These biomaterials were conspicuously tested in many body sites in the last century, and largely in the ear [6, 7]. The fate of bioinert biocompatible biomaterials is to elicit a minimal inflammatory reaction and be ultimately surrounded by a thin dense collagenous capsule [28]. However, a highly aggressive microenvironment caused by chronic pathologies is present in the outer and middle ear, which has always challenged any durable applications of bioinert bulk devices for otologic applications [7]. In further generation biomaterials, porosity has been considered as a key feature at the device/tissue interface able to promote tissue and vasculature ingrowth in place of a fibrotic 

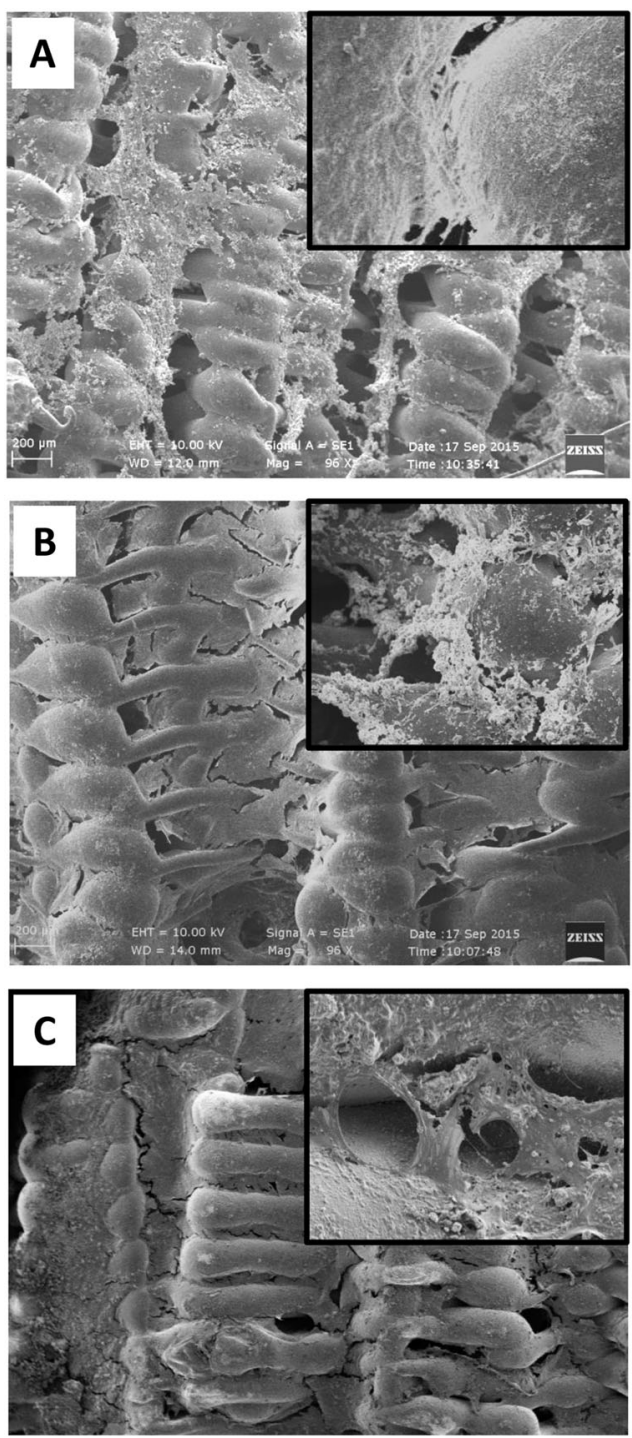

Fig. 6 SEM micrographs of osteoinduced hMSC/EAC wall scaffold constructs, as obtained according to 3 different seeding strategies: hMSCs suspended in gelatin and seeded in 3 steps (strategy "a") (a); hMSCs suspended in gelatin and seeded in 2 steps (strategy "b") (b); hMSCs suspended in plasma and seeded in 3 steps (strategy "c") (c). Lens show cellular details at $\times 500$ magnification

capsule, which ultimately enabled the concept of porous scaffolds for TE. The influence of porosity and pore size of the EAC wall scaffolds is not largely documented in literature. It is a fact that examples of TE scaffolds for ear applications are quite recent, if compared to other organs [8-12]. Studies performed in the nineties by van Blitterswijk et al. [29] on porous hydroxylapatite ear implants, including EAC wall prostheses, showed that the pores were filled by new bone, firmly bonded to the hydroxyapatite interface. Such implants were reported to have $31 \%$ porosity, distributed as $5 \%$ microporosity (pore diameter $<5$ $\mu \mathrm{m}$ ) and $26 \%$ macroporosity (pore diameter $>5 \mu \mathrm{m}$ ). Macropores were filled with bone, fibrous tissue and exudate, the latter due to ear infections. For scaffolds designed for bone applications, the optimal pore size and porosity are not consensual in literature, even if pores ranging in 100-300 $\mu \mathrm{m}$ and above, but lower than $1000 \mu \mathrm{m}$, are recommended to allow new bone ECM and capillary formation [30]. It can be expected that highly porous scaffolds provided with hundred micron-to-submillimeter pores will allow fast regeneration and vascularization at the implantation site, whereas both smaller and larger pores will favor fibrous tissue infiltration. Due to the specific anatomy of the ear, the accomplishment of high porosity and pore interconnectivity, as well as hundreds-micron pore size within thin and curve shapes can be really challenging [9]. This study showed that semicircular porous PEOT/PBT copolymer scaffolds with $1.72 \pm 0.23 \mathrm{~mm}$ overall thickness and $200 \pm 33 \mu \mathrm{m}$ diameter fibers could be fabricated via $3 \mathrm{DF}$ as a manufacturing techniques. The best scaffold, obtained using G27 needle, had averagely 55\% gravimetric and about $39.5 \%$ volumetric porosity, as the result of interconnected pores of $\sim 200 \mu \mathrm{m}\left(=\mathrm{d}_{2}-\mathrm{d}_{1}\right)$, the latter being in line with the optimal pore size for bone regeneration. Moreover, the produced scaffolds showed surface/volume ratio 8 times higher than that of bulk device, which is supportive of sufficient surface porosity for interacting with the surrounding tissues. Even though the micro-CT measurements showed fiber thickness and SD higher than those obtained via SEM, it has to be noted that SEM and microCT outcomes are independent measurements with different precision and accuracy. In particular, the micro-CT based local thickness measurements is based on the method of Hildebrand et al. [22]. Briefly, this method aims to find the largest sphere fully contained in the micro-CT segmented structure at a given point to express the local thickness at that point. Mean and SD of local thickness over the entire structure are then reported. In this work, the reported average micro-CT local fiber thickness can therefore include the contribution of the contact points between the fibers, where the maximal sphere is generally larger than that passing through an isolated fiber.

A copolymer of PEOT/PBT family was first applied as an eardrum replacement in a rat model in the nineties showing interesting outcomes [31]. A salt-casted film with $100 \mu \mathrm{m}$ thickness, $50 \%$ porosity and $160 \mu \mathrm{m}$ pore size, which induced a mild foreign body reaction after implantation, followed by epithelialization, showed $50 \%$ biodegradation in one year timeframe. This biomaterial was tested under Staphylococcus aureus-induced middle ear infection, thus highlighting potential for otologic applications and corroborating the choice of PEOT/PBT copolymer family for EAC wall manufacture, which should comply with the several facets of biocompatibility, including sufficient stability in an inflamed environment to allow new tissue growth. 
Fig. 7 Micrographs showing the histological outcomes, specifically: a H\&E staining and b von Kossa staining of osteoinduced hMSC/EAC wall scaffold constructs, as obtained according to three different seeding strategies: (1) hMSCs suspended in gelatin and seeded in 3 steps (strategy "a"); (2) hMSCs suspended in gelatin and seeded in 2 steps (strategy "b"); (3) hMSCs suspended in plasma and seeded in 3 steps (strategy "c")
A

H\&E

A1

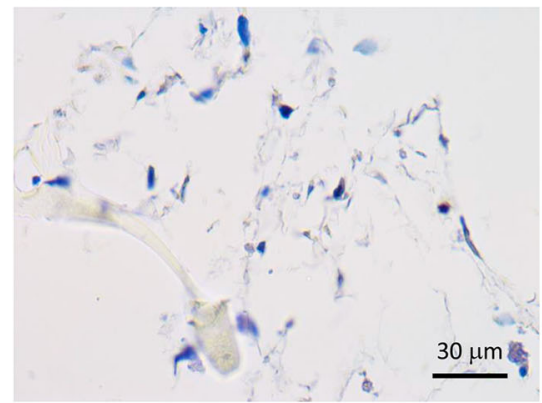

A2

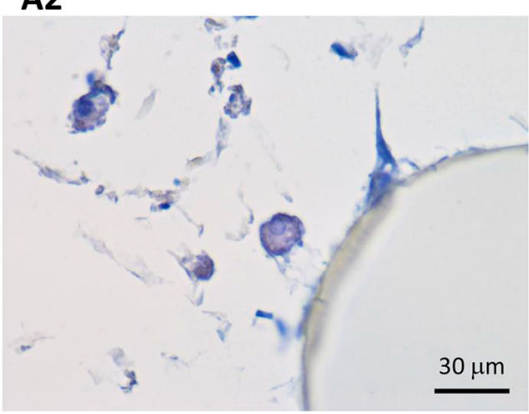

A3

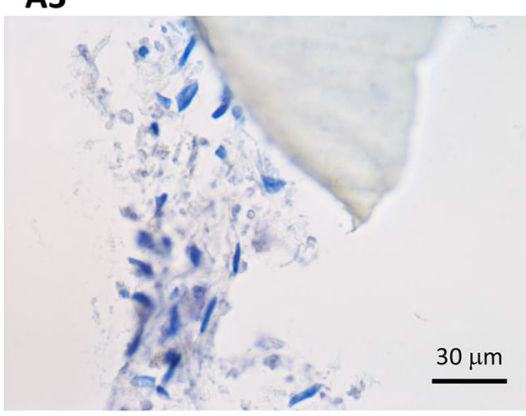

B Von Kossa

B1

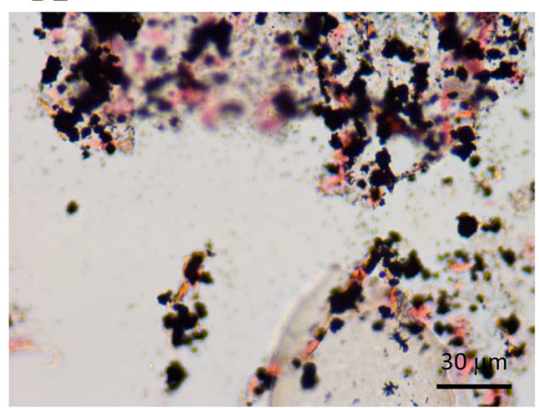

B2

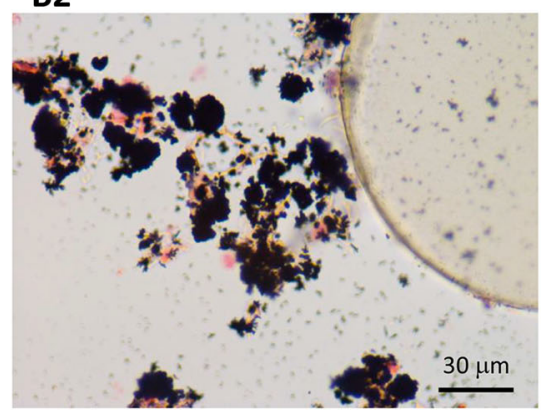

B3

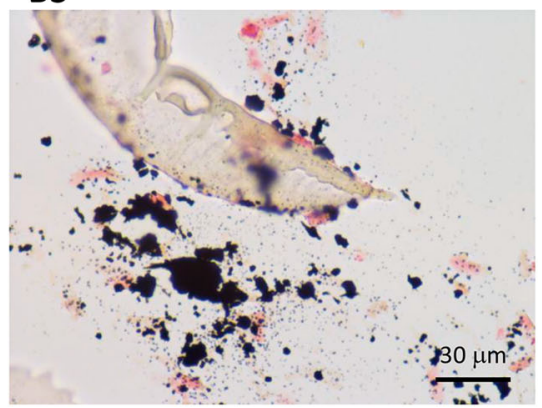

As a non-load bearing bone, EAC wall prosthesis has a reduced demand in terms of necessary mechanical properties. However, since porosity can remarkably affect the mechanical behavior of materials, in this study the compressive modulus of cylindrical samples fabricated with the same pattern and needle of EAC wall scaffolds was evaluated to ensure compliance of the device structural integrity with the implantation procedure. The obtained compressive modulus, $25.1 \pm 7.0 \mathrm{MPa}$, is of the order of magnitude reported for stiff cartilage [32]. As such, the produced scaffolds can be considered mechanically similar but still less stiff than the native EAC wall, which is osseo-cartilage. A mechanical compatibility with the surrounding tissues is also desirable for an improved biocompatibility [28]. The chosen fabrication strategy, including copolymer and production parameters, allowed the accomplishment of architectural and mechanical features theoretically suitable for this application. However, the stiffness of the polymeric scaffold may be further enhanced by incorporating hydroxyapatite nano-particles in order to match the stiffness of trabecular bone [33].

Therefore, in vitro experiments were carried out to investigate preliminary biological interactions of the EAC wall scaffold with hMSCs under osteogenic commitment. Indeed, it is expected that resident cells will repopulate the scaffolds and produce ECM, to reach the final compositional and mechanical characteristics of EAC wall. In particular, the inner two thirds of EAC has very thin epidermis, lacks of ceruminous glands and is made of bone, not cartilage. Therefore, bone regeneration appears the most important event for this application. In fact, in vivo studies using porous implants for EAC wall reconstruction reported the infiltration of bony tissue [29]. Owing to the large volume and surface area, cell seeding was performed on real size EAC wall scaffolds using multiple steps, namely, either two or three seeding steps, each one consisting of several 
shots distributed along the body of the scaffold, which ultimately led to twelve million hMSCs seeded in each sample. Three seeding strategies were tested, including cells suspended in a gelatin aqueous solution with two different time schedules, or in pooled plasma, the latter transformed right after into a clot by crosslinking with calcium chloride to minimize cell loss [27]. Using a viable dye in between each seeding time-point permitted the empty areas to be localized, to which the second and third seeding shots were applied. In the end, all the scaffolds resulted uniformly colonized and vital hMSCs could be observed inside the pores. Under osteogenic commitment for 21 days, the cells remained viable and were able to produce a thick layer of mineral matrix with nodular appearance, as revealed by SEM and von Kossa staining, without appreciable differences among the diversely seeded samples. This biological study showed preliminary evidence supporting the use of 3DF scaffolds for EAC wall reconstruction and will hopefully pave the way for novel effective otologic devices and procedures using TE substitutes.

\section{Conclusions}

This study demonstrated the fabrication feasibility of EAC wall scaffolds aimed to match several important requirements for biomaterial application to the ear under the TE paradigm, including shape, porosity and pore size, surface area, mechanical properties and favorable in vitro interaction with osteo-differentiated hMSCs. Fiber size and scaffold porosity were optimized, leading to $200 \pm 33 \mu \mathrm{m}$ and $55 \% \pm 5 \%$, respectively. The compressive modulus was $25.1 \pm 7.0 \mathrm{MPa}$, which is lower than that of the EAC as an osseocartilaginous tissue, but still in the order of stiff cartilage. HMSCs uniformly colonized the scaffolds and produced mineral matrix within the fibers. The possibility of producing curve porous thin and sufficiently strong structures with high accuracy of external geometry and internal pore architecture by means of 3DF techniques may allow in the future the production of customized ear implants of improved biocompatibility and functionality.

\footnotetext{
Acknowledgements The Italian Ministry of University and Research (MIUR, PRIN 2010S58B38) and the Tuscany Region (Health Program 2009 and CUCCS 2014) are greatly acknowledged for funding this research. S.D. and D.P. would like to thank the ARPA Foundation young researchers' award, Decree \#21, 20 December 2011, Medicine Faculty, University of Pisa. This research project received support from the Dutch Province of Limburg. Dr. Delfo D'Alessandro (University of Pisa) is kindly acknowledged for his remarkable technical support to histologic analysis.
}

Author contributions C.M., L.B., and S.D. designed the experiments. C.M., M.M., D.P., L.T., and S.D. performed the experiments. C.M., M.M., D.P., and L.T. analyzed the data. C.M., V.G., and S.D. drafted the manuscript. P.A.S., S.G., C.S., L.M., and S.B. provided reagents and tools.

\section{Compliance with ethical standards}

Conflict of interest The authors declare that they have no conflict of interest.

\section{References}

1. Fatterpekar GM, Doshi AH, Dugar M, Delman BN, Naidich TP, Som PM. Role of 3D CT in the Evaluation of the Temporal Bone. Radiogrphics. 2006;26(S1):17-32. https://doi.org/10.1148/rg. 26 si065502

2. Chatra P. Lesions in the external auditory canal. Indian J Radiol Imaging. 2011;21(4):274. https://doi.org/10.4103/0971-3026. 90687

3. Dankuc D, Vlaski L, Pejakovic N. Techniques of the tympanomastoidectomy with reconstruction of the posterior bone wall of the external auditory canal. Srp Arh Celok Lek. 2015;143 (7-8):480-6. https://doi.org/10.2298/SARH1508480D

4. Heywood R, Narula A. The pros and cons of canal wall up versus canal wall down mastoidectomy for cholesteatoma. Otorhinolaryngologist. 2013;6(3):140-3.

5. Wullstein SR, Schindler K, Döll W. Further observations on application of "plasticin" in ear surgery. In: Grote JJ, editor. Biomaterials in otology. Leiden: Springer Netherlands; 1984. p. 250-61. https://doi.org/10.1007/978-94-009-6756-4_30

6. Dormer KJ, Gan RZ. Biomaterials for implantable middle ear hearing devices. Otolaryngol Clin North Am. 2001;34:289-97.

7. Beutner D, Hüttenbrink KB. Passive and active middle ear implants. GMS Curr Top Otorhinolaryngol Head Neck Surg. 2009;8:Doc09.

8. Danti S, Stefanini C, D'Alessandro D, Moscato S, Pietrabissa A, Petrini M, et al. Novel biological/biohybrid prostheses for the ossicular chain: fabrication feasibility and preliminary functional characterization. Biomed Micro. 2009;11(4):783-93. https://doi. org/10.1007/s10544-009-9293-9

9. Danti S, D'Alessandro D, Pietrabissa A, Petrini M, Berrettini S. Development of tissue-engineered substitutes of the ear ossicles: PORP-shaped poly(propylene fumarate)-based scaffolds cultured with human mesenchymal stromal cells. J Biomed Mater Res A. 2010;92(4):1343-56. https://doi.org/10.1002/jbm.a.32447

10. Mota C, Danti S, D’Alessandro D, Trombi L, Ricci C, Puppi D, et al. Multiscale fabrication of biomimetic scaffolds for tympanic membrane tissue engineering. Biofabrication. 2015;7(2):025005 https://doi.org/10.1088/1758-5090/7/2/025005

11. Danti S, Mota C, D'alessandro D, Trombi L, Ricci C, Redmond SL, et al. Tissue engineering of the tympanic membrane using electrospun PEOT/PBT copolymer scaffolds: a morphological in vitro study. Hear, Balance Commun. 2015;13(4):133-47. https://doi.org/10.3109/21695717.2015.1092372

12. Zein I, Hutmacher DW, Tan KC, Teoh SH. Fused deposition modeling of novel scaffold architectures for tissue engineering applications. Biomaterials. 2002;23(4):1169-85. https://doi.org/ 10.1016/S0142-9612(01)00232-0

13. Moroni L, Poort G, Van Keulen F, de Wijn JR, van Blitterswijk CA. Dynamic mechanical properties of 3D fiber-deposited PEOT/ PBT scaffolds: an experimental and numerical analysis. J Biomed Mater Res A. 2006;78(3):605-14. https://doi.org/10.1002/jbm.a. 30716

14. Moroni L, de Wijn JR, van Blitterswijk CA. Three-dimensional fiber-deposited PEOT/PBT copolymer scaffolds for tissue engineering: influence of porosity, molecular network mesh size, and 
swelling in aqueous media on dynamic mechanical properties. $\mathbf{J}$ Biomed Mater Res A. 2005;75(4):957-65. https://doi.org/10. 1002/jbm.a.30499

15. Moroni L, de Wijn JR, van Blitterswijk CA. 3D fiber-deposited scaffolds for tissue engineering: influence of pores geometry and architecture on dynamic mechanical properties. Biomaterials. 2006;27(7):974-85. https://doi.org/10.1016/j.biomaterials.2005. 07.023

16. Moroni L, Curti M, Welti M, Korom S, Weder W, de Wijn JR, et al. Anatomical 3D fiber-deposited scaffolds for tissue engineering: designing a neotrachea. Tissue Eng. 2007;13 (10):2483-93. https://doi.org/10.1089/ten.2006.0385

17. Moroni L, Schotel R, Hamann D, de Wijn JR, van Blitterswijk CA. 3D fiber-deposited electrospun integrated scaffolds enhance cartilage tissue formation. Adv Funct Mater. 2008;18(1):53-60. https://doi.org/10.1002/adfm.200601158

18. Agarwal S, Wendorff JH, Greiner A. Progress in the field of electrospinning for tissue engineering applications. Adv Mater. 2009;21 (32-33):3343-51. https://doi.org/10.1002/adma.200803092

19. Moroni L, de Wijn JR, van Blitterswijk CA. Integrating novel technologies to fabricate smart scaffolds. J Biomater Sci Polym Ed. 2008;19(5):543-72. https://doi.org/10.1163/156856208784089571

20. Woodfield TB, Miot S, Martin I, van Blitterswijk CA, Riesle J. The regulation of expanded human nasal chondrocyte redifferentiation capacity by substrate composition and gas plasma surface modification. Biomaterials. 2006;27(7):1043-53. https:// doi.org/10.1016/j.biomaterials.2005.07.032

21. Odgaard A. Three-dimensional methods for quantification of cancellous bone architecture. Bone. 1997;20(4):315-28.

22. Hildebrand T, Ruegsegger P. A new method for the modelindependent assessment of the thickness in three-dimensional images. J Microsc. 1997;185(1):67-75.

23. Panetta D, Belcari N, Del Guerra A, Bartolomei A, Salvadori PA. Analysis of image sharpness reproducibility on a novel engineered micro-CT scanner with variable geometry and embedded recalibration software. Phys Med. 2012;28(2):166-73. https://doi.org/ 10.1016/j.ejmp.2011.03.006

24. Doube M, Kłosowski MM, Arganda-Carreras I, Cordelières FP, Dougherty RP, Jackson JS, Schmid B, Hutchinson JR, Shefelbine
SJ. BoneJ: Free and extensible bone image analysis in Image. J Bone. 2010;47(6):1076-9. https://doi.org/10.1016/j.bone.2010.08. 023

25. Schneider CA, Rasband WS, Eliceiri KW. NIH Image to ImageJ: 25 years of image analysis. Nat Methods. 2012;9(7):671-5. https://doi.org/10.1038/nmeth.2089

26. Jerabek M, Major Z, Lang RW. Uniaxial compression testing of polymeric materials. Polym Test. 2010;29:302-9.

27. Trombi L, Danti S, Savelli S, Moscato S, D'Alessandro D, Ricci $\mathrm{C}$, et al. Mesenchymal stromal cell culture and delivery in autologous conditions: a smart approach for orthopedic applications. J Vis Exp. 2016. https://doi.org/10.3791/54845

28. Williams DF. On the mechanisms of biocompatibility. Biomaterials. 2008;29:2941-53.

29. Van Blitterswijk CA, Hesseling SC, Grote JJ, Koerten HK, de Groot K. The biocompatibility of hydroxyapatite ceramic: a study of retrieved human middle ear implants. J Biomed Mater Res. 1990;24(4):433-53. https://doi.org/10.1002/jbm.820240403

30. Karageorgiou V, Kaplan D. Porosity of 3D biomaterial scaffolds and osteogenesis. Biomaterials. 2005;26(27):5474-91. https://doi. org/10.1016/j.biomaterials.2005.02.002

31. Bakker D, van Blitterswijk CA, Hesseling SC, Th. Daems W, Kuijpers W, Grote JJ. The behavior of alloplastic tympanic membranes in Staphylococcus aureus-induced middle ear infection. I. Quantitative biocompatibility evaluation. J Biomed Mater Res. 1990;24(6):669-88. https://doi.org/10.1002/jbm.820240604

32. Barker MK, Seedhom BB. The relationship of the compressive modulus of articular cartilage with its deformation response to cyclic loading: does cartilage optimize its modulus so as to minimize the strains arising in it due to the prevalent loading regime? Rheumatology. 2001;40(3):274-84. https://doi.org/10. 1093/rheumatology/40.3.274

33. De Santis R, D'Amora U, Russo T, Ronca A, Gloria A, Ambrosio L. 3D fibre deposition and stereolithography techniques for the design of multifunctional nanocomposite magnetic scaffolds. J Mater Sci. 2015. https://doi.org/10.1007/s10856-015-5582-4. 